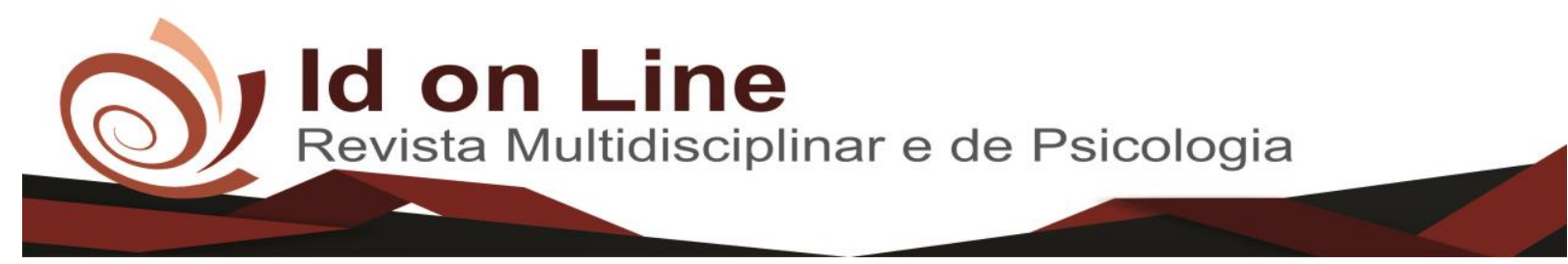

Comment

\title{
Desmistificando as Fissuras Labiopalatinas
}

\author{
Jônatas Peireira do Pradoㅁ, Jade Alexandre Belo Reus², Ana Flávia Soares ${ }^{2}$; \\ Gyselle Cynthia Silva Meireles Lemos ${ }^{3}$
}

Resumo: A fissura palatina é um dos defeitos congênitos mais comum em humanos. Os portadores de fissuras labiopalatinas apresentam alterações anatômicas e funcionais, que interferem no desenvolvimento psicológico, fisiológico e na adaptação social. A falha na fusão entre os processos nasais mediais e os processos maxilares resulta em fissura labial, e a falta de coalescência nas placas palatinas provoca a fissura palatina. O presente trabalho tem como objetivo salientar a importância do controle da ansiedade frente ao tratamento odontológico através de uma revisão de literatura atual., para determinar o número pacientes portadores dessas fissuras, investigando nestes pacientes o sexo, classificação socioeconômica, tipo de fissura e lado afetado, e sua relação ou não com síndromes.

Palavras-chave: Fenda labial. Fissura palatina. Prevalência.

\section{Demystifying Labiopalatine Fissure}

Abstract: The cleft palate is one of the most common congenital defects in humans. The patients with cleft lip and palate present anatomical and functional alterations that interfere in the psychological, physiological and social adaptation. The production failure between the industries and maxillary processes results in labial cleft, and the lack of coalescence in the palatine plates causes a cleft palate. To determine the number of patients with fissures, investigating the patients in relation to sex, socioeconomic classification, type of fissure, and type of fissure. affected side, and its relationship or not with syndromes.

Keywords: Lip cleft. Cleft palate. Prevalence.

\section{Introdução}

As fissuras labiopalatinas são malformações congênitas que ocorrem devido a distúrbios no crescimento de processos teciduais que devem se unir e fusionar no período embrionário (NEVILLE et al, 2004).

\footnotetext{
${ }^{1}$ Graduando em Odontologia da Faculdade Independente do Nordeste - FAINOR. jonatas@ fainor.com.br.

${ }^{2}$ Graduando em Odontologia da Faculdade Independente do Nordeste - FAINOR

${ }^{3}$ Especialista, Mestre e Doutora em Endodontia pela Universidade de São Paulo - USP/Bauru, Docente do Curso de Odontologia da Faculdade Independente do Nordeste - FAINOR.

${ }^{3}$ Doutora em Odontologia pela Universidade Federal da Bahia - UFBA, Docente da Universidade Estadual da Bahia - UESB e do Curso de Odontologia da Faculdade Independente do Nordeste - FAINOR.
}

229 Id on Line Rev. Mult. Psic. V.12, N. 42, Supl. 1, p. 229-241, 2018 - ISSN 1981-1179 
O desenvolvimento do lábio superior ocorre entre a sexta e sétima semana de vida intra-uterina, enquanto a formação do palato se dá até a décima segunda semana. A falha na fusão entre os processos nasais mediais e os processos maxilares resulta em fissura labial, e a falta de coalescência nas placas palatinas provoca a fissura palatina (NEVILLE et al, 2004).

A formação de fissuras labiopalatinas é um dos defeitos congênitos mais comuns em humanos (NEVILLE et al, 2004) e no Brasil tem uma prevalência de 0,19 por mil nascidos vivos (LOFFREDO et al, 2001).

A etiologia das fissuras labiopalatinas mais aceita é a teoria multifatorial e se resume na interação de fatores genéticos e ambientais (GRAZIOSI et al, 2000). Acredita-se que o fator hereditário seja o principal, mas fatores ambientais como idade, consanguinidade dos pais, doenças sistêmicas, infecções, uso de medicamentos, deficiência nutricional, estresse, hábitos e vícios dos pais, entre outros, devem ser levados em consideração (GRAZIOSI et al, 2000).

$\mathrm{Na}$ literatura encontram-se muitos sistemas de classificação das fissuras labiopalatinas (RODRIGUES et al, 2005), e uma classificação que usualmente é utilizada no Brasil é a de Spina et al (1972), com base no desenvolvimento embriológico, definindo as fissuras por sua extensão, tendo como referência anatômica o forame incisivo (RODRIGUES et al, 2005; BAPTISTA, 2007). Segundo os autores, no grupo das fissuras pré-forame incisivo, estão as fissuras localizadas anteriormente ao forame incisivo, podendo atingir o lábio e o rebordo alveolar. Podem ser completas quando abrangem o assoalho nasal e atingem o forame incisivo, e incompletas quando atingem somente o lábio. Podem ainda ser classificadas como unilaterais direita ou esquerda e, bilaterias, de acordo com o lado afetado. Ainda classificam as fissuras em transforame e pós-forame incisivo.

A forma mais complexa das fissuras é a completa de lábio e palato bilateral, pois divide a maxila em três segmentos: dois palatinos e um central que constitui a pré-maxila. Neste tipo de fissura, o septo nasal encontra-se exposto, havendo comunicação entre as cavidades nasal e bucal, necessitando de um maior número de cirurgias para uma total reparação (RODRIGUES et al, 2005).

Por terem uma origem multifatorial, as fissuras labiopalatinas podem acometer todos os grupos raciais e étnicos, independente da classe econômica e do sexo (HUSSNE, 2004). A frequência das fissuras labiopalatinas é mais elevada em asiáticos comparada aos indivíduos brancos e mais baixa em indivíduos negros (NEVILLE et al, 2004). Um estudo feito sobre a 
prevalência de fissuras orais no Brasil apontou a fissura labial ou a labiopalatina como mais encontrada que a fissura palatina isolada (LOFFREDO et al, 2001). Em geral, as fissuras são mais comumente encontradas em pessoas do sexo masculino (FREITAS et al, 2004; FREITAS e SILVA et al, 2008). Quanto à classe social, estudos mostraram que a maior parte dos portadores de fissuras labiopalatinas pertencia ao nível sócioeconômico baixo (BARONEZA et al, 2005; CERQUEIRA et al, 2005).

Os portadores de fissuras labiopalatinas, além do comprometimento estético e da comunicação verbal, apresentam alterações anatômicas e funcionais, que interferem no desenvolvimento psicológico, fisiológico e na adaptação social (FREITAS e SILVA et al, 2008; MIRANDA et al, 2004). Por este motivo, o tratamento das fissuras labiopalatinas deve ser cirúrgico e não-cirúrgico e requer uma atuação multiprofissional especializada e integrada, incluindo um pediatra, cirurgião maxilofacial, otorrinolaringologista, cirurgião plástico, odontopediatra, ortodontista, protesista, nutricionista, psicólogo, fonoaudiólogo e geneticista (MELGAÇO et al, 2002; NEVILLE et al, 2004; RIBEIRO;MOREIRA, 2005; FREITAS e SILVA et al, 2008).

Ante o exposto nos indagamos: quais as principais considerações da literatura acerca das fissuras palatinas, desde sua embriologia, etiologia, associação com síndromes até sua prevalência no Brasil?

\section{Metodologia}

É sabido que as fissuras labiopalatinas são determinadas ainda na vida uterina, no qual ocorre distúrbios no crescimento teciduais que deveriam unir e fusionar ainda nessa fase da vida. Por ser um defeito congênito muito comum entre humanos, essa condição merece destaque e contínuo estudos (MELGAÇO, 2002).

Nesse sentido, este trabalho tem por objetivo discutir, através de uma revisão de literatura atual, a embriologia, etiologia, classificação socioeconômica, tipo de fissura e lado afetado, e a relação ou não com síndromes diversas e as fissuras labiopalatinas,

Alguns artigos foram buscados nas bases de dados online, assim como materiais em livros didáticos de autores renomados na Odontologia, nos idiomas português e inglês, utilizando-se 
as palavras-chaves fissuras labiopalatinas, síndrome e epidemiologia, privilegiando àqueles dos últimos 18 anos, que se encaixavam no perfil de inclusão deste trabalho. Os autores que contribuíram para esta revisão crítica, estão dispostos na tabela 1, a seguir.

Tabela 1 - Artigos que fizeram parte desta revisão crítica

\begin{tabular}{|c|c|c|c|}
\hline Autor(es) & Título & Periódico & Ano \\
\hline BARONEZA, J. E. et al. & $\begin{array}{l}\text { Dados epidemiológicos de } \\
\text { portadores de fissuras } \\
\text { labiopalatinas de uma } \\
\text { instituição especializada de } \\
\text { Londrina, Estado do Paraná. }\end{array}$ & $\begin{array}{l}\text { Acta Sci Health Sci, v.27, n.1, } \\
\text { p.31-35, }\end{array}$ & \\
\hline $\begin{array}{l}\text { CERQUEIRA, M. N. et } \\
\text { al. }\end{array}$ & $\begin{array}{l}\text { Ocorrência de fissuras } \\
\text { labiopalatais na cidade de São } \\
\text { José dos Campos - SP. }\end{array}$ & $\begin{array}{l}\text { Rev Bras Epidemiol, v.8, n.2, } \\
\text { p. } 161-166 .\end{array}$ & 2005 \\
\hline CYMROT, M. et al. & $\begin{array}{l}\text { Prevalência dos tipos de fissura } \\
\text { em pacientes com fissuras } \\
\text { labiopalatinas atendidos em um } \\
\text { Hospital Pediátrico do } \\
\text { Nordeste Brasileiro. }\end{array}$ & $\begin{array}{l}\text { Rev Bras Cir Plast, v.25, n.4, } \\
\text { p.648-651. }\end{array}$ & 2010 \\
\hline $\begin{array}{l}\text { FRANÇA, C. M. C.; } \\
\text { LOCKS, A. }\end{array}$ & $\begin{array}{l}\text { Incidência das fissuras lábio- } \\
\text { palatinas de crianças nascidas } \\
\text { na cidade de Joinvile (SC) no } \\
\text { período de } 1994 \text { a } 2000 .\end{array}$ & $\begin{array}{l}\text { J Bras Ortodont Ortoped Fac, } \\
\text { v.8, n.47, p.429-436. }\end{array}$ & 2003 \\
\hline $\begin{array}{l}\text { FREITAS e SILVA, D. } \\
\text { S. et al. }\end{array}$ & $\begin{array}{l}\text { Estudo descritivo de fissuras } \\
\text { lábio-palatinas relacionadas a } \\
\text { fatores individuais, sistêmicos } \\
\text { e sociais. }\end{array}$ & RGO, v.56, n.4, p. 387-391 & 2008 \\
\hline FREITAS, J. A. S. et al. & $\begin{array}{l}\text { Current data on the } \\
\text { characterization of oral clefts in } \\
\text { Brazil. }\end{array}$ & $\begin{array}{l}\text { Braz Oral Res, v.18, n.2, } \\
\text { p.128-133 }\end{array}$ & 2004 \\
\hline GALLBACH, J. R. & $\begin{array}{l}\text { Paciente com fissura } \\
\text { labiopalatina: potencial de } \\
\text { resolutividade do atendimento } \\
\text { na Faculdade de Odontologia } \\
\text { da UFMG. 2004. 128f. }\end{array}$ & $\begin{array}{l}\text { Dissertação (Mestrado em } \\
\text { Odontologia - Área de } \\
\text { concentração: Saúde Coletiva) } \\
\text { - Faculdade de Odontologia, } \\
\text { Universidade de Minas Gerais, }\end{array}$ & 2004 \\
\hline $\begin{array}{l}\text { GRAZIOSI, M. A. O. C.; } \\
\text { SALGADO, M. A. C.; } \\
\text { CASTILHO, J. C. M. }\end{array}$ & $\begin{array}{l}\text { Investigação epidemiológica } \\
\text { em indivíduos portadores de } \\
\text { fendas labiais e/ou palatinas. }\end{array}$ & $\begin{array}{l}\text { Pós-Grad Rev Fac Odontol São } \\
\text { José dos Campos, v.3, n.1, } \\
\text { p.81-87. }\end{array}$ & 2000 \\
\hline $\begin{array}{l}\text { LOFFREDO, L. C. M. et } \\
\text { al. }\end{array}$ & $\begin{array}{l}\text { Fissuras lábio-palatais: estudo } \\
\text { caso-controle. }\end{array}$ & $\begin{array}{l}\text { Rev Saúde Pública, v.28, n.3, } \\
\text { p.213-217. }\end{array}$ & 1994 \\
\hline $\begin{array}{l}\text { LOFFREDO, L. C. M.; } \\
\text { FREITAS, J. A. S.; } \\
\text { GRIGOLLI, A. A. G. }\end{array}$ & $\begin{array}{l}\text { Prevalência de fissuras orais de } \\
1975 \text { a } 1994 .\end{array}$ & $\begin{array}{l}\text { Rev Saúde Pública, v. 35, n.6, } \\
\text { p. 571-575. }\end{array}$ & 2001 \\
\hline MELGAÇO, C. A. et al. & $\begin{array}{l}\text { Aspectos } \\
\text { ortodônticos/ortopédicos e }\end{array}$ & $\begin{array}{l}\text { J Bras Ortodon Ortop Facial, v. } \\
7, \text { n.37, p.23-32. }\end{array}$ & 2002 \\
\hline
\end{tabular}




\begin{tabular}{|c|c|c|c|}
\hline & $\begin{array}{l}\text { fonoaudiológicos relacionados } \\
\text { a pacientes portadores de } \\
\text { fissuras labiopalatinas. }\end{array}$ & & \\
\hline NEVES, A. C. C., et al. & $\begin{array}{l}\text { Prevalência das fissuras } \\
\text { labiopalatinas na Associação } \\
\text { de Fissurados Labiopalatinos } \\
\text { de São José dos Campos/S.P. }\end{array}$ & Rev biociênc, v.8, n.2, p.69-74. & 2002 \\
\hline NEVILLE, B. W. et al. & Patologia Oral e Maxilofacial. & $\begin{array}{l}\text { Livro: 2. ed. Rio de Janeiro: } \\
\text { Guanabara Koogan, 798p. }\end{array}$ & 2004 \\
\hline $\begin{array}{l}\text { SANDRINI, F. A. L. et } \\
\text { al. }\end{array}$ & $\begin{array}{l}\text { Estudo familiar de pacientes } \\
\text { com anomalias associadas às } \\
\text { fissuras labiopalatinas no } \\
\text { Serviço de Defeitos da Face da } \\
\text { Pontifícia Universidade } \\
\text { Católica do Rio Grande do Sul. }\end{array}$ & $\begin{array}{l}\text { Rev Cir Traumatol Buco- } \\
\text { Maxilo-Fac, v. 6, n.2, p. 57-68. }\end{array}$ & \\
\hline $\begin{array}{l}\text { SILVA FILHO, O. M. et } \\
\text { al. }\end{array}$ & $\begin{array}{l}\text { Classificação das fissuras } \\
\text { lábio-palatais: breve histórico, } \\
\text { considerações clínicas e } \\
\text { sugestão de modificação. }\end{array}$ & $\begin{array}{l}\text { Rev Bras Cir, v.82, n.2, p.59- } \\
65 .\end{array}$ & 1992 \\
\hline
\end{tabular}

Fonte: Pesquisa dos autores, 2018.

Com relação aos artigo, observou-se que, 2 (13,3\%) artigos foram de ates de 1994 (inclusive); 4 (26,7\%) artigos foram de 1994 a 1998 (inclusive); 7 artigos (46,7\%) foram dos anos de 2002 a 2006 (inclusive); 2 artigos (13,3\%) são dos anos de 2006 a 2010 (inclusive).

Portanto a maioria dos artigos foram publicados entre os anos de 2002 a 2006, demonstrando uma real necessidade de mais publicações sobre essa temática, que atualize o assunto na literatura.

\section{Resultados}

\section{Embriologia das fissuras labiopalatinas}

A formação da face e cavidade oral é de natureza complexa, e distúrbios no crescimento ou fusão de processos teciduais podem resultar em formação de fendas labiopalatinas. (NEVILLE et al, 2004).

Aproximadamente no final da quarta semana de vida intra-uterina, inicia-se a formação do centro da face, ocorrendo a formação dos processos nasais mediano e lateral. Durante a sexta e sétima semana do desenvolvimento, ocorre a formação do lábio superior, em decorrência da 
fusão dos processos nasais medianos entre si e com os processos maxilares do primeiro arco branquial. Uma falha na fusão do processo nasal mediano com o processo maxilar resulta em fissura labial (NEVILLE et al, 2004).

A formação do palato primário também se dá pela união dos processos nasais medianos, formando o segmento intermaxilar, que dará origem à pré-maxila, que contém os dentes incisivos. O palato secundário constitui a maior parte do palato, e é originado dos processos maxilares do primeiro arco branquial. Por volta da sexta semana de vida intra-uterina, projeções bilaterais emergem das porções medianas dos processos maxilares, formando as prateleiras palatinas. Durante a oitava semana, com o crescimento das porções anteriores destas prateleiras, estas se fundem uma com a outra e também com o palato primário e o septo nasal, completando esta união aproximadamente na décima segunda semana de vida intra-uterina. Uma falha na fusão das prateleiras palatinas resulta em fissura palatina. É observada, frequentemente, a ocorrência de fissura labial associada à fissura palatina (NEVILLE et al, 2004).

\section{Etiologia das fissuras labiopalatinas}

Para explicar a etiologia das fissuras labiopalatinas, atualmente os pesquisadores defendem a teoria multifatorial, ocorrendo a combinação de determinantes genéticos e fatores ambientais (GRAZIOSI et al, 2000).

LOFFREDO et al, 1994, realizaram um estudo caso-controle com o objetivo de pesquisar possíveis fatores de risco para as fissuras orais. Os autores estudaram a associação entre fissuras orais e as variáveis: história familiar de fissura, história de parentesco entre os pais, morar na zona rural, exposição à poluição, história de epilepsia nos pais, ocorrência de doenças na mãe nos 4 primeiros meses de gestação, ingestão de medicamentos pela mãe, incluindo antiinflamatórios, consumo de bebida alcoólica pela mãe, habito de fumar dos pais, entre outros. Os resultados indicaram como fatores de risco para a fissura labial ou labiopalatina a hereditariedade, a epilepsia na mãe e a ingestão de antiinflamatórios nos 4 primeiros meses de gestação. Os autores ainda ressaltaram a importância da hereditariedade, pois esta e poluição foram considerada fatores de risco para a fissura palatina.

234 Id on Line Rev. Mult. Psic. V.12, N. 42, Supl. 1, p. 229-241, 2018 - ISSN 1981-1179 Edição eletrônica em http://idonline.emnuvens.com.br/id 
Segundo Graziosi et al (2000), a etiologia das fissuras labiopalatinas tem como base a interação de fatores genéticos-ambientais, e fatores como idade e consangüinidade dos pais, doenças sistêmicas, infeções e uso de medicamentos, radiações, deficiência nutricional, estresse, estação do ano, hábitos e vícios dos pais, profissão dos mesmos e nível socioeconômico, devem ser levados em consideração

\section{Associação das fissuras labiopalatinas com síndromes}

$\mathrm{Na}$ maior parte dos casos, as fissuras labiopalatinas ocorrem de maneira isolada. Mas, já forma identificadas mais de 250 síndromes que podem estar associadas com fendas labiais ou fendas palatinas isoladas, ou com fendas labiopalatinas. Acredita-se que estas síndromes sejam responsáveis por 3 a $8 \%$ das fendas orofaciais, principalmente fendas labiopalatinas (NEVILLE et al, 2004).

CERQUEIRA et al, em 2005, realizaram um estudo sobre a ocorrência de fissuras labiopalatinas na cidade de São José doa Campos - SP, observando que de todos os casos levantados, 9,18\% estavam associados a alguma síndrome, sendo a Síndrome de Pierre Robin a mais prevalente.

SANDRINI et al, em 2006, fizeram um estudo familiar de pacientes com anomalias associadas às fissuras labiopalatinas atendidas na Pontifícia Universidade Católica do Rio Grande do Sul, constatando que dois pacientes apresentaram Sindrome de Van der Woude e outro apresentou Sequência de Pierre Robin. Estes autores ainda ressalvam a importância de realizar aconselhamento genético nos pacientes portadores de anomalias associadas às fissuras labiopalatinas.

\section{Classificação das fissuras labiopalatinas}

Um sistema de classificação das fissuras labiopalatinas deve procurar aliar simplicidade, objetividade e clareza na descrição dos diferentes tipos de fissura (GALLBACH, 2004). 
A classificação de Spina (1972) tem base no desenvolvimento embriológico, e nesta classificação, as fissuras são divididas em quatro grupos: no grupo 1 estão as fissuras préforame incisivo que envolvem o lábio e/ou rebordo alveolar e podem ser unilaterais direita ou esquerda, completa ou incompleta, bilateral completa ou incompleta, mediana completa ou incompleta; no grupo 2 estão as fissuras transforame incisivo, envolvendo lábio e palato, podendo ser uni ou bilaterais; no grupo 3 estão as fissuras pós-forame incisivo, que podem ser completas ou incompletas; e no grupo 4 são encontradas as fissuras raras da face.

No ano de 1992, Silva Filho et al, propuseram uma modificação na classificação de Spina et al, acrescentando a fissura mediana ao grupo da fissura transforme incisivo. Desta maneira, os autores definiram esta classificação como a mais completa.

\section{Epidemiologia das fissuras de lábio e palato}

$\mathrm{Na}$ literatura são encontrados diversos trabalhos realizados com a finalidade de avaliar a prevalência de fissuras labiopalatinas em diferentes grupos populacionais.

LOFFREDO et al, em 2001, fizeram um estudo sobre a prevalência de fissuras orais no Brasil, em diferentes regiões geográficas, no período de 1975 a 1994. Os autores encontraram uma prevalência de 0,19 por mil nascidos vivos. As regiões Centro-Oeste, Sul e Sudeste apresentaram as maiores taxas, sendo que esta última contribuiu com $61 \%$ dos casos. A região Nordeste apresentou as menores taxas de prevalência do país. A fissura labial ou labiopalatina foi mais frequente, com 74\%, comparada à fissura palatina isolada (26\%).

NEVES et al., (2002), estudaram a prevalência das fissuras labiopalatinas em uma associação de fissurados na cidade de São José dos Campos - SP, relacionando o tipo de fissura com o sexo, mês de nascimento, hereditariedade e uni ou bilateralidade das fissuras. Os resultados demonstraram que a fissura transforame foi a que mostrou maior incidência, não sendo evidenciada relação estatística significativa entre o tipo de fissura e o sexo dos pacientes. As fissuras labiopalatinas incidiram com maior frequência no sexo masculino $(60,15 \%)$ que no sexo feminino (39,83\%). Também não foi demonstrada relação entre o tipo de fissura e a variável hereditariedade. Foi observada ainda maior incidência de fissuras unilaterais que 
bilaterais, e relação estatística significativa foi encontrada entre os tipos de fissura e a uni ou bilateralidade destas, assim como entre os tipos de fissura e o mês do nascimento dos pacientes.

FRANÇA e LOCKS, em 2003, realizaram um trabalho para verificar a incidência de fissuras labiopalatinas sem síndrome associada, em crianças nascidas na cidade de Joinvile SC, no período de 1994 a 2000. Os resultados apontaram que a incidência de fissura labiopalatina foi de 1,24 por 1000 nascidos vivos. Não houve diferença estatística entre os sexos. A fissura mais prevalente foi a transforame incisivo (40,28\%), seguida pela fissura transforame incisivo $(30,56 \%)$, pela fissura pré-forame incisivo $(22,22 \%)$, fissura pré e pósforame incisivo $(4,17 \%)$ e por último a fissura mediana $(2,78 \%)$. Fissuras unilaterais foram mais encontradas que as bilaterais, e o lado esquerdo foi o mais acometido.

Em 2004, FREITAS et al publicaram informações atuais sobre a caracterização das fissuras orofaciais no Brasil. Foram examinados pacientes não operados que compareceram pela primeira vez ao Hospital de Reabilitações de Anomalias Craniofaciais, em Bauru, no ano de 2000. Os autores observaram predominância de fissura completa de lábio e palato $(37,1 \%)$, sendo $24,9 \%$ unilaterais e $12,2 \%$ bilaterais, seguida pela fissura de palato isolada $(31,7 \%)$ e fissura de lábio isolada (28,4\%). Em geral, as fissuras foram mais comumente encontradas em indivíduos do sexo masculino (cerca de 60\%), somente as fissuras e palato isoladas foram mais predominantes em pacientes do sexo feminino $(53,2 \%)$.

BARONEZA et al, em 2005, demonstraram dados epidemiológicos de portadores de fissuras labiopalatinas de uma instituição especializada em Londrina - PR. Para isso, foram avaliadas a prevalência das fissuras em relação ao gênero, ao hábito materno de fumar até o $3^{\circ}$ mês de gestação, à história familiar de fissuras, à classificação socioeconômica e as faixas etárias materna e paterna no período da concepção. Os autores encontraram a fissura transforame como a mais prevalente $(59,9 \%)$. A razão entre os gêneros encontrada foi de 1,5 para o masculino e 1,0 para o feminino. A maior parte dos pacientes $(92,6 \%)$ pertencia à classe econômica baixa, constituindo este, portanto, um fator de risco para a ocorrência de fissuras. As idades maternas e paternas foram respectivamente $25,5 \pm 7,0$ e 29,8 \pm 8,9 anos. Os autores ainda ressaltaram que no Brasil ainda são poucas as instituições que propiciam cuidados específicos para deficientes faciais, e este fator poderia acarretar na falta de acompanhamento destes pacientes em função da distância que devem percorrer até o centro mais próximo. 
CERQUEIRA et al, em 2005, analisaram a ocorrência de fissuras labiopalatais em uma associação de apoio a pacientes com fissura, na cidade de São José dos Campos, no estado de São Paulo. Foram levantados dados de fichas de 200 crianças, e os autores observaram que não houve diferença na ocorrência de fissuras com relação ao sexo da criança e a fissura mais prevalente foi a pós-forame incompleta. Os autores ainda encontraram que crianças de classe socioeconômica desfavorecida foram mais acometidas e que aproximadamente um décimo do total estudado apresentou relação com alguma síndrome.

FREITAS e SILVA et al, em 2008, realizaram um estudo descritivo de fissuras labiopalatinas relacionadas a fatores individuais, sistêmicos e sociais em um centro especializado na cidade de São Paulo. Os resultados indicaram que $60 \%$ da população amostral eram do sexo masculino, e $92 \%$ da raça branca. A fissura mais prevalente neste estudo foi a transforame incisivo com $62 \%$ dos casos e as fissuras unilaterais foram mais frequentes, totalizando $65,5 \%$, sendo o lado esquerdo o mais afetado, constituindo $44,3 \%$ dos casos.

Em 2010, CYMROT et al estudaram a prevalência dos tipos de fissura em pacientes portadores de fissuras labiopalatinas atendidos em um Hospital pediátrico na cidade de Fortaleza - CE. Os autores observaram que a maior parte da população amostral pertencia ao sexo masculino (53\%). Dentre todos os tipos de fissuras, as transforames foram as mais prevalentes $(72,6 \%)$. Em relação ao lado afetado, as fissuras esquerdas $(61,3 \%)$ foram mais frequentes que as direitas. Foi observada também uma maior prevalência de fissura transforame no sexo masculino e de fissura pós-forame no sexo feminino.

\section{Considerações Finais}

Diante das elucidações evidenciadas neste trabalho, infere-se que as fissuras labioplatinas possuem etiologia multifatoria, mas tem seu acontecimento ainda na vida intrauterina. No qual há erro durante os processos de união e fusão de estruturas primordiais para lábio e palato, como os processos nasais mediais e os processos maxilares ou a falta de coalescência nas placas palatinas. É válido ressaltar, que em algumas situações essa condição clínica estará associada à algumas Síndromes, sendo, portanto, fator intrínseco da mesma.

238 Id on Line Rev. Mult. Psic. V.12, N. 42, Supl. 1, p. 229-241, 2018 - ISSN 1981-1179 Edição eletrônica em http://idonline.emnuvens.com.br/id 
Apesar de possuir uma etiologia multifatorial, o que de certa forma, dificulta o prognóstico do tratamento, essa condição clínica evidencia a associação de fatores genéticos e ambientais. No Brasil, há um valor significativo nos índices de prevalência da fissura labiopalatinas, em que há um caso a cada 0,19 mil nascidos vivos. Tal condição, torna notório a real importância dos constantes estudos relacionados à mesma.

O resultado evidenciou a importância de maiores e mais atuais estudos sobre esse tema. Haja vista, que a tecnologia oferece, cada vez mais, dados e métodos eficientes para o tratamento, nas situações de fissuras labiopalatinas, que possam melhorar a qualidade de vida dos portadores de tal anomalia.

\section{Referências}

BAPTISTA, E. V. P. Malformações congênitas associadas à fissura labial e/ou palatal em pacientes atendidos em um serviço de referência para tratamento de defeitos da face: um estudo de série de casos. 2007. 67f. Dissertação (Mestrado em Saúde da criança) - Instituto Materno Infantil Prof. Fernando Figueira - IMIP, 2007.

BARONEZA, J. E. et al. Dados epidemiológicos de portadores de fissuras labiopalatinas de uma instituição especializada de Londrina, Estado do Paraná. Acta Sci Health Sci, v.27, n.1, p.31-35, 2005.

CERQUEIRA, M. N. et al. Ocorrência de fissuras labiopalatais na cidade de São José dos Campos - SP. Rev Bras Epidemiol, v.8, n.2, p. 161-166, 2005.

CYMROT, M. et al. Prevalência dos tipos de fissura em pacientes com fissuras labiopalatinas atendidos em um Hospital Pediátrico do Nordeste Brasileiro. Rev Bras Cir Plást, v.25, n.4, p.648-651, 2010.

DIÁRIO DO SUDOESTE DA BAHIA. Prefeitura assina contrato com Fundação de saúde. Disponível em: <http://www.dsvc.com.br/2012/destaques/prefeitura-assina-contrato-comfundacao-de-saude/>. Acesso em: 11 jun. 2012.

FRANÇA, C. M. C.; LOCKS, A. Incidência das fissuras lábio-palatinas de crianças nascidas na cidade de Joinvile (SC) no período de 1994 a 2000. J Bras Ortodont Ortoped Fac, v.8, n.47, p.429-436, 2003.

FREITAS, J. A. S. et al. Current data on the characterization of oral clefts in Brazil. Braz Oral Res, v.18, n.2, p.128-133, 2004. 
FREITAS e SILVA, D. S. et al. Estudo descritivo de fissuras lábio-palatinas relacionadas a fatores individuais, sistêmicos e sociais. RGO, v.56, n.4, p. 387-391, 2008.

GALLBACH, J. R. Paciente com fissura labiopalatina: potencial de resolutividade do atendimento na Faculdade de Odontologia da UFMG. 2004. 128f. Dissertação (Mestrado em Odontologia - Área de concentração: Saúde Coletiva) - Faculdade de Odontologia, Universidade de Minas Gerais, 2004.

GRAZIOSI, M. A. O. C.; SAlGADO, M. A. C.; CASTILHO, J. C. M. Investigação epidemiológica em indivíduos portadores de fendas labiais e/ou palatinas. Pós-Grad Rev Fac Odontol São José dos Campos, v.3, n.1, p.81-87, 2000.

HUSSNE, R. P. Estudo das necessidades, planejamento e prognóstico endodôntico em pacientes fissurados de lábio e/ou palato submetidos ao tratamento cirúrgico. 2004. 100f. Dissertação (Mestrado em Odontologia - Área de concentração: Endodontia) - Faculdade de Odontologia de Araraquara, Universidade Estadual Paulista “Júlio de Mesquita Filho", 2004.

LOFFREDO, L. C. M. et al. Fissuras lábio-palatais: estudo caso-controle. Rev Saúde Pública, v.28, n.3, p.213-217, 1994.

LOFFREDO, L. C. M.; FREITAS, J. A. S.; GRIGOLLI, A. A. G. Prevalência de fissuras orais de 1975 a 1994. Rev Saúde Pública, v. 35, n.6, p. 571-575, 2001.

MELGAÇO, C. A. et al. Aspectos ortodônticos/ortopédicos e fonoaudiológicos relacionados a pacientes portadores de fissuras labiopalatinas. J Bras Ortodon Ortop Facial, v. 7, n.37, p.23$32,2002$.

MIRANDA, G. E. et al. Caracterização dos pacientes acometidos por fissura labiopalatina atendidos por um projeto de extensão dâ FO-UFMG. J Bras Ortodon Ortop Facial, v.9, n.52, p. 398-404, 2004.

NEVES, A. C. C. Prevalência das fissuras labiopalatinas na Associação de Fissurados Labiopalatinos de São José dos Campos/S.P. Rev biociênc, v.8, n.2, p.69-74, 2002.

NEVILLE, B. W. et al. Patologia Oral \& Maxilofacial. 2. ed. Rio de Janeiro: Guanabara Koogan, 2004. 798p.

SANDRINI, F. A. L. et al. Estudo familiar de pacientes com anomalias associadas às fissuras labiopalatinas no Serviço de Defeitos da Face da Pontifícia Universidade Católica do Rio Grande do Sul. Rev Cir Traumatol Buco-Maxilo-Fac, v. 6, n.2, p. 57-68, 2006.

RIBEIRO, E. M.; MOREIRA, A. S. C. G. Atualização sobre o tratamento multidisciplinar das fissuras labiais e palatinas. RBPS, v.18, n.1, p. 31-40, 2005.

RODRIGUES, M. R. et al. Fissura completa bilateral: características morfológicas. Rev Odontol UNESP, v.34, n.2, p.67-72, 2005. 
SPINA, V. et al. Classificação das fissuras labio-palatinas. Sugestão de modificação. Rev Hosp Clin Fac Med São Paulo, v. 27, n.1, p. 5-6, 1972.

SILVA FILHO, O. M. et al. Classificação das fissuras lábio-palatais: breve histórico, considerações clínicas e sugestão de modificação. Rev Bras Cir, v.82, n.2, p.59-65, 1992.

\section{Como citar este artigo (Formato ABNT):}

PRADO, Jônatas Peireira do; RODRIGUES, Clarissa Teles; LEMOS, Gyselle Cynthia Silva Meireles. Desmistificando as Fissuras Labiopalatinas. Id on Line Rev.Mult. Psic., 2018, vol.12, n.42, Supl. 1, p. 229-241. ISSN: 1981-1179.

Recebido: 02/11/2018;

Aceito: 05/11/2018 